Área Abierta. Revista de comunicación

audiovisual y publicitaria

ISSN: 2530-7592 / ISSNe: 1578-8393

\title{
El papel del consultor en las producciones audiovisuales publicitarias en España durante el periodo de crisis económica (2008-2016)
}

\author{
Jorge Clemente Mediavilla ${ }^{1}$ y Ana Visiers Elizaincin ${ }^{2}$
}

Recibido: 27 de mayo de 2018 / Aceptado: 12 de julio de 2018

Resumen. La presente investigación analiza el papel del Cost controller de los anunciantes en los procesos de producción audiovisual publicitaria en España durante la crisis económica de 2008. El estudio trata de observar si en los últimos años se ha producido un aumento de anunciantes que recurren a sus servicios y con qué objetivo. Examinar su papel en el proceso, su formación y la forma en la que son retribuidos. La investigación se realiza a través de veintitrés entrevistas en profundidad a profesionales del sector: anunciantes, consultores, agencias, productoras y postproductoras. Serán ellos mismos los que detallen el trabajo de los consultores y las ventajas y desventajas de su labor. Todo ello con la intención de mejorar los procesos de producción y, por tanto, la calidad de las producciones audiovisuales publicitarias.

Palabras clave: Consultor; producción audiovisual; publicidad; anunciante; crisis económica

\section{[en] The role of the Cost controller in advertising audiovisual productions in Spain during the period of economic crisis (2008-2016)}

\begin{abstract}
The present investigation analyzes the role of the Cost controller in the processes of audiovisual advertising production in Spain during the economic crisis of 2008. The study focuses on observing whether in recent years the advertising companies have been increasing the use of Cost controller services or not, and with what objective. It also examines their role in the process, their training and the retribution alternatives. The study is conducted through twenty-three in-depth interviews with professionals of the industry: advertisers, consultants, agencies, producers and post-producers. These professionals themselves will detail the work of the Cost controller, and the advantages and disadvantages of their work. All this is done with the intention of improving production processes and therefore the quality of audiovisual advertising productions.
\end{abstract}

Keywords: Cost controller; audiovisual production; advertising; advertiser; economic crisis

Sumario. 1. Introducción. 2. Objetivo. 3. Metodología. 4. Marco Teórico. 5. Resultados de la investigación. 6. Conclusiones. 7. Bibliografía.

Cómo citar: Clemente Mediavilla, J; Visiers Elizaincin, A. (2019) El papel del consultor en las producciones audiovisuales publicitarias en España durante el periodo de crisis económica (2008-2016), en Área Abierta. Revista de comunicación audiovisual y publicitaria 19 (2), 127-143. http://dx.doi. org/10.5209/ARAB.60463

\footnotetext{
$1 \quad$ Universidad Complutense de Madrid (España)

E-mail: jclemen@ucm.es

2 Centro Universitario Villanueva (España)

E-mail: Avisiers@yahoo.es
} 


\section{Introducción}

El proceso de producción audiovisual publicitario responde a un protocolo en el que todos los que participan saben qué lugar ocupan y qué labores deben desempeñar para el correcto desarrollo de un spot, desde que el anunciante encarga a la agencia de publicidad una campaña hasta su emisión en televisión.

Debido a la crisis económica, se comenzaron a apreciar una serie de cambios en esos procesos. En primer lugar, la inversión de los anunciantes se vio reducida de manera significativa, como se puede observar en el siguiente gráfico.

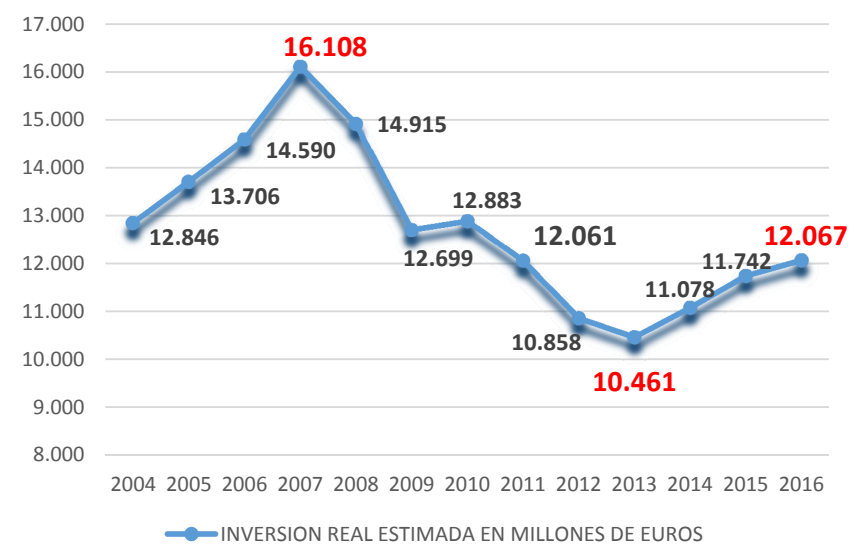

Ilustración 1. Evolución de la inversión publicitaria (2004-2016).

Fuente: Elaboración propia con datos de InfoAdex

Desde el año 2004 hasta el 2007 se registra un crecimiento constante de la inversión real estimada del mercado publicitario. En 2007 alcanza la cifra de 16.108 millones de euros, lo que supone un incremento del 9,2\% sobre la cifra del 2006. Sin embargo, en 2008 el informe anual de InfoAdex destaca la disminución de la inversión y lo explica de este modo:

Estos datos demuestran que la inversión publicitaria continúa presentando una alta sensibilidad a las etapas de crisis, ya que en un entorno de significativa disminución de la tasa de crecimiento de la economía (la estimación provisional es de un crecimiento del PIB del orden de $1,2 \%$ en 2008 frente al 3,7\% de 2007) muestra una significativa contracción de su volumen. (InfoAdex, 2009)

Es en 2013 cuando la inversión publicitaria alcanza la cifra más baja desde el comienzo de la crisis económica, llegando a la cifra de 10.461 millones de euros, casi 6.000 millones de euros menos que en 2007. Ya en 2014 se comienza a ver una ligera recuperación de la inversión publicitaria y en el informe de 2017 cifran en 12.067 millones de euros la inversión de 2016. "La inversión publicitaria, en este 2016 que presentamos, se encuentra de nuevo en los niveles que tenía en el año 2000, después de sufrir una caída superior al 52\% entre 2008 y 2013" (InfoAdex, 2017). 
Por este motivo, la presente investigación ha sido enmarcada en el periodo 20082016: se ha considerado que desde 2014 se ha producido una recuperación de la inversión publicitaria, pero las consecuencias de la crisis económica en la publicidad se mantienen por lo menos hasta el año 2016.

Como consecuencia de tal crisis, la disminución de la inversión afectó a la remuneración de las agencias y directamente a los presupuestos destinados a las producciones audiovisuales. Además, la relación de los anunciantes con las agencias ha pasado por fases de desconfianza que en muchos casos se han traducido en la incorporación de nuevos protagonistas del proceso de producción.

\section{Objetivo}

Partiendo de la hipótesis de que los anunciantes se habrían planteado recurrir cada vez con mayor asiduidad a Cost controllers para ajustar los presupuestos de producción audiovisual, la presente investigación se propone analizar las figuras del Cost controller y consultor del anunciante. No se trata de analizar cuántos anunciantes han incorporado los servicios de un Cost controller: se trata de conocer el porqué, qué ha llevado a tomar esas decisiones, y en qué medida afecta todo ello al proceso de producción; y por supuesto, con la intención de detectar aquellas faltas, opacidades u obstáculos que entorpecen el proceso de producción.

\section{Metodología}

La técnica elegida para desarrollar esta investigación ha sido la metodología cualitativa: se considera que los propios protagonistas del proceso de producción podrían facilitar toda la información necesaria para dar respuesta a las hipótesis planteadas.

Asimismo, sirve como referencia para la elección de la metodología de este estudio, el uso de la aproximación cualitativa en la investigación de Benavides, Villagra, Alameda y Fernández Blanco (2010). Los autores analizan la gestión de la publicidad de diversos anunciantes españoles. Los objetivos principales de su estudio son:

Conocer el papel de la actividad publicitaria en la estructura general de la empresa, analizar las relaciones del anunciante con los agentes implicados en el sector de la comunicación e identificar los principales problemas que replantean el actual sistema publicitario hacia nuevos métodos de trabajo. (Benavides et al., 2010)

$\mathrm{Y}$ al igual que en el estudio citado, esta investigación recoge todas esas experiencias a través de entrevistas en profundidad. De forma inductiva, como dice Ruiz Olabuénaga (2012), porque se entiende que el interés no está en llegar a resultados que permitan generalizar, sino en la captación de la realidad en su contexto recogida a través de diversas experiencias.

Estas entrevistas se realizan a personas conocedoras del proceso de producción publicitaria antes y después de la crisis económica. De acuerdo a la definición de Valles (2002) que centra las entrevistas "en las experiencias subjetivas de la gente expuesta a la situación, con el propósito de contrastar las hipótesis y averiguar res- 
puestas o efectos no anticipados" (p. 20), se plantean entrevistas focalizadas en los actores principales del proceso audiovisual. ¿Quién mejor que los protagonistas para hablar de este proceso?

Y, como lo que se pretende con la investigación es comprender, se realizan entrevistas semiestructuradas, para tener la libertad de profundizar en unos temas y desarrollar otros aspectos que pueden surgir durante la conversación. Se realizan siguiendo un esquema, en el que el orden y la formulación de las preguntas pueden ser diferentes al entrevistar a los distintos sujetos.

Se alternan preguntas abiertas que dan libertad de respuesta al entrevistado, y cerradas, en las que se trata de verificar determinadas informaciones (Ruiz Olabuénaga, 2012).

La presente investigación se realiza a través de un total de veintitrés entrevistas en profundidad a profesionales dentro de cada una de las fases de producción publicitaria.

Y teniendo en cuenta los criterios muestrales que recoge Valles (2009), se llega a la elección de la siguiente muestra:

1. Anunciantes de marcas líderes en su sector.

2. Cost controller y Consultores del anunciante.

3. Directores de producción de agencia y Producers.

4. Directores de cuentas y directores creativos ejecutivos de agencias nacionales y multinacionales.

5. Productoras.

6. Postproductoras.

\begin{tabular}{|c|c|c|}
\hline ANUNCIANTES & AGENCIA & PRODUCTORA \\
\hline ANUNCIANTE 1 & CREATIVO 1 & PRODUCTORA 1 \\
\hline ANUNCIANTE 2 & CREATIVO 2 & PRODUCTORA 2 \\
\hline ANUNCIANTE 3 & CREATIVO 3 & PRODUCTORA 3 \\
\hline PRODUCER ANUNCIANTE 1 & CUENTAS 1 & PRODUCTORA 4 \\
\hline PRODUCER ANUNCIANTE 2 & PRODUCER 1 & POSTPRODUCTORA \\
\hline COST CONTROLLER 1 & PRODUCER 2 & POSTPRODUCTORA 1 \\
\hline CONSULTOR 1 & PRODUCER 3 & POSTPRODUCTORA 2 \\
\hline CONSULTOR 2 & PRODUCER 4 & POSTPRODUCTORA 3 \\
\hline
\end{tabular}

Ilustración 2. Casillero tipológico: Selección de la muestra de acuerdo a la cadena de producción. Fuente: elaboración propia.

Los anunciantes entrevistados abarcan la mayoría de los sectores que más inversión publicitaria realizan cada año: automoción, finanzas, alimentación, belleza e higiene, telecomunicaciones e internet, bebidas y hogar. Han realizado en total unas seis mil producciones a lo largo de una media de veintisiete años. Asimismo, y para diversificar en mayor medida la muestra, los Cost controller, consultores y los profesionales de las agencias seleccionados no están trabajando en la actualidad para los anunciantes entrevistados.

En el caso de los tres directores creativos entrevistados, todos ellos llevan más de ciento veinticinco campañas de televisión realizadas, y han recibido numerosos premios en distintos festivales publicitarios. Entre creativos y cuentas han trabaja- 
do para más de cien anunciantes. Todos los Producers entrevistados, como puede observarse, llevan más de veinte años trabajando en el sector. Algunos comenzaron en productora y pasaron a trabajar en agencias, y en la actualidad solo uno de ellos trabaja dentro de la estructura de la agencia.

Y, por último, se han seleccionado productores ejecutivos de productoras grandes y medianas. Una de ellas puede ser probablemente la que más spots ruede cada año en España y llevan casi treinta años produciendo anuncios y recibiendo numerosos premios en los festivales más importantes nacionales e internacionales. Al igual que las postproductoras, dos de ellas con un volumen de facturación y muchos años de recorrido en España, y una tercera, con un profesional que lleva muchos años en el sector y a cargo ahora de una postproductora también consolidada en nuestro país. Con muchas producciones realizadas por todos ellos en más de veinticuatro años de profesión de media, su experiencia con cientos de anunciantes y agencias ha sido fundamental para la realización de esta investigación.

Un requisito indispensable ha sido que todos ellos fueran conocedores de la forma de producir antes de la crisis económica del 2008 y en la actualidad y, debido en muchos casos a sus cargos, que pudieran dedicar una media de noventa minutos para realizar la entrevista. Las entrevistas se llevaron a cabo entre octubre de 2016 y marzo de 2017.

\section{Marco Teórico}

Son escasas las investigaciones que entran a analizar la labor de este consultor del anunciante. Para los profesionales del sector son personas con nombre y apellido, con distintas funciones y trabajando de distinta forma dependiendo del anunciante. Sin embargo, los estudios encontrados en su mayoría hacen mención a la tendencia del anunciante a introducir en sus estructuras a estos profesionales (Solanas y Sabaté, 2011; Oejo, 1998), pero no profundizan en la labor que desempeñan.

Lo cierto es que, aunque en Estados Unidos los anunciantes cuentan con los Cost controller para sus producciones audiovisuales desde hace más de treinta años, en España ha sido en los últimos quince o veinte años cuando algunos anunciantes empiezan a contar con sus servicios.

Para los autores consultados, el motivo de esta nueva tendencia fue sin duda la demanda de transparencia por parte del anunciante, debido a la sospecha de que "cierto porcentaje de la producción audiovisual acababa en las arcas de las agencias en lugar de emplearse en recursos para el proyecto" (Carvajal, 2009: 190).

Brierley (2005) recoge en su libro la actuación de Unilever en 1992, que causó gran revuelo al introducir un auditor para que actuara como Consultor en setenta producciones. Estos nuevos Consultores eran ex-empleados de las agencias de publicidad, lo que puso de manifiesto la falta de confianza de los anunciantes hacia sus agencias.

En España, en un principio, la actividad del Cost controller empezó a ser desarrollada por personal del departamento de compras de las empresas. Se pretendía valorar de forma cuantitativa los gastos en los que se incurría al realizar un anuncio. Por tanto, el control se centraba exclusivamente en los presupuestos de producción. En 2005 McCann realiza una declaración en la que afirma que habían recibido comisiones del 15\% sobre las producciones sin que los anunciantes los supieran. Por esta 
razón, es lógico que el papel del Cost controller en ese momento fuera supervisar que en las producciones de su anunciante no había un cargo de esa comisión.

Ese mismo año García-Clairac (2005) ya hacía mención a estos controles económicos: "aunque le corresponde a la agencia aceptar los presupuestos, algunos anunciantes suelen tener sus propios controles de producción y hacen su valoración personal. Los anunciantes desean saber si están pagando el precio justo por lo que compran, y esto obliga a afinar" (García-Clairac, 2005: 84).

No obstante, su poca o nula experiencia en lo que a producción audiovisual se refiere, como apunta Carvajal (2016), dio como resultado "que no llegaron a entender totalmente la naturaleza del medio, priorizando los criterios cuantitativos sobre los criterios cualitativos. Ello siempre ha despertado resquemor hacia su figura que, ha sido tomada siempre como el responsable de los recortes en el presupuesto" (Carvajal, 2016: 39).

Quizá por esta imagen negativa podemos decir que, en los últimos años, ellos mismos han comenzado a denominarse Consultores en vez de Cost controller, y de esta forma ampliar su labor, no como meros controladores del presupuesto, sino como veladores de la calidad y coste de las producciones.

Carvajal (2016) lo define así:

La figura del Consultor depende directamente de la compañía anunciante, a quien prestará sus servicios y, según se acuerde en su contrato, será el responsable de asesorar en la optimización del proceso de producción de un proyecto audiovisual en términos técnicos, económicos, operativos, legales y corporativos, sin interferir en la parte creativa, que es responsabilidad única de la agencia. (Carvajal, 2016: 40)

Asimismo, es importante que todos los que intervienen en el proceso sepan de la existencia de este profesional y se le considere parte del equipo del anunciante. Normalmente, según asegura Carvajal (2016) el Consultor empezará a trabajar en el proceso en el momento en que la agencia presenta al anunciante las opciones de productoras con las que quiere rodar el spot:

Antes de conceder un proyecto de producción, la agencia ha de someter a revisión por parte del anunciante, o de su Consultor en caso de que lo tuviese, el presupuesto de la casa productora seleccionada. El anunciante/Consultor se asegurarán de que esta valoración incluya todos los usos y requerimientos antes de dar su aprobación. (Carvajal, 2016: 69)

Será en este momento cuando su labor será más relevante, ya que deberá analizar los presupuestos corroborando que todas las necesidades de la producción y de lo que se ha solicitado en el briefing audiovisual están cubiertas. Todo ello, sin olvidar la calidad que espera conseguir el anunciante y el calendario de producción y emisión del spot. Así mismo, deberá "desestimar aquellos conceptos o partidas que no cumplan con esa misión” (Carvajal, 2016: 200).

La figura del Consultor debe estar en estrecha relación con el Producer de la agencia, que es el interlocutor entre la agencia y el anunciante, y la productora. 
En el proceso de recepción de las ofertas, el Consultor deberá interactuar con el Producer de la agencia, informándole de cualquier concepto recogido en los planteamientos de las productoras que, pueda no reflejar la realidad técnica o económica del mercado, con el fin de que la productora subsane el error y la documentación que llegue a la reunión, cumpla con las expectativas generales. (Carvajal, 2016: 213)

En algunos casos los anunciantes llegan a acuerdos con casas de postproducción, y lo normal es que en esas producciones la labor del Cost controller no vaya más allá del rodaje. Sin embargo, si su acuerdo es hasta la entrega del spot en la fase de postproducción "su responsabilidad será la de supervisar que se están administrando bien los tiempos, los medios tecnológicos y los recursos, conforme a lo estipulado en el presupuesto" (Carvajal, 2016: 244).

Aunque en estos últimos años se ha percibido un cambio en las funciones de los Cost controller en España, durante muchos años su figura no ha sido del todo bien recibida en las producciones. Se puede apreciar una gran diferencia en la manera que tiene Cury (2013) de definir su labor en Estados Unidos. Cury denomina a esta figura "Client/Producer" y lo define como aquel profesional con experiencia en producción de cine o televisión que se responsabiliza de las necesidades diarias de la producción de un anuncio. Es el nexo entre el anunciante y la agencia durante el proceso de producción audiovisual. Cury explica que no todos tienen las mismas responsabilidades, depende de la empresa, pero principalmente está al servicio de la creatividad. Participa desde el principio del proceso y no tiene la última palabra sobre cada toma del rodaje, pero sí le suelen solicitar su opinión, al igual que en el montaje y la postproducción, hasta que el spot es apto para ser emitido. E incluso, dependiendo de la forma de pago de la producción, se encargará de las facturas comprobando los gastos de cada producción. También afirma que es estricto en la revisión de cada una de las partidas de presupuesto, no en vano, justifica su sueldo al encontrar aquellas partidas que pueden hacer ahorrar dinero al anunciante. En opinión de Cury (2013) este profesional cliente/productor sirve a las necesidades de la agencia de publicidad, así como a la productora, pero siempre velando por la empresa. La mayoría de las veces es un experto en la producción y, por tanto, su opinión es esperada y valorada.

Con esta descripción, podría entenderse que su papel, lejos de tener que desagradar a nadie, debería verse como una gran ayuda a la producción por parte de todos los que intervienen en ella.

Lola Casadevall, en una entrevista realizada por IPMARK, lo explica así: "La agencia tiene Producer, la productora tiene Producer, pero la mayoría de anunciantes no tiene Producer. Al fin y al cabo, son tres interlocutores con un mismo lenguaje. Incorporando la figura del Producer en cliente se mejora el resultado, ya que el cliente tiene comunicación directa también con productora, siempre siguiendo los procesos de producción establecidos y estando la agencia al corriente de toda la información" (Under Control Producers, 2015).

Por tanto, parece que la justificación inicial de la introducción de esta figura por esa percepción del anunciante de poca transparencia, daría paso a considerar su labor como recomendable para el buen entendimiento de cliente, agencia y productora, sin entrar a valorar el ahorro real en las producciones que puedan producir con su control presupuestario. 
Porque la realidad es que, en esta fase del estudio, no se han encontrado documentos ni bibliografía en la que se explique si forman o no parte de la plantilla de la empresa, y en el caso de que sean externos, cuál es la forma en la que se les retribuye su trabajo.

\section{Resultados de la investigación}

\subsection{Motivos por los que surgen los Cost controller en España}

Para los profesionales del sector los primeros Cost controller que empiezan a trabajar en España surgen alrededor del año 2000. Sus funciones se reducían a la optimización del presupuesto de producción. "Recibía la creatividad, recibía el presupuesto y negociaba ese presupuesto. Pero esa negociación era: los hoteles en vez de a 5 pónmelos a 4, y no entraba en el diseño de producción. No entraba en el control de la producción desde el principio hasta el final", explica Consultor 2.

Los motivos por los que surge esta figura son puramente económicos y así se demuestra si se tiene en cuenta que la única función que desempeñaban era la de revisar el presupuesto de las productoras para conseguir una optimización del mismo.

Para Anunciante 2, se ha intensificado por las mismas estructuras de las empresas, por la externalización de los departamentos de producción: "Tantos actores distintos entrando a un departamento de producción que ya no existe, una empresa nueva. Es todo tan complejo que en mi opinión al final el cliente tiene la sensación de que está perdiendo el control. Ya no sabe qué le están ofreciendo". Anunciante 2 justifica así los servicios de su Cost controller:

Cuando ves dos o tres cosas extrañas que, a lo mejor, yo no digo que sean intencionadas, pueden ser errores. Pero ves que hay cosas que no cuadran, partidas que te cobran y luego vas al rodaje y no están. La sensación era de mucha inseguridad y yo creo que con la crisis se ha intensificado esa sensación, y es la que hace que entre la figura del Cost controller, que yo creo que cada vez es más normal. (Anunciante 2)

No obstante, si se analiza el motivo de obtener la seguridad de que se están empleando bien los recursos económicos del anunciante, la pregunta que cabe hacerle es si cree que la productora está encareciendo los procesos o buscando un mayor beneficio industrial o, por el contrario, se refiere a una parte del presupuesto que no llega a la productora y se queda en la agencia. Anunciante 2 opina que:

Hay un poco de todo. Siempre se ve que el mundo de la producción es opaco y dentro de este mundo de la producción hay muchos bulos. Entre que todos hemos trabajado en varios sitios y que al final no deja de ser un mundo pequeño, se hablan, se comentan casos. Y al final ahí hay algo, que no se sabe qué es, oscuro, y no se termina de saber si es la productora con la agencia, si la agencia aprovecha y en este momento busca meter un poco más porque el fee no es suficiente y aquí puedo sacar una tajada. La agencia te dice que no te engaña, tú piensas que sí. Y luego hay bulos. Productoras que afirman que las agencias les amenazan: si no pones este fee no trabajo más contigo. 
De este modo explica el clima de desconfianza que ya se ha comentado. Pero añade un tema preocupante que también comentan otros anunciantes internacionales: "Lo que está pasando es que muchas veces se está saliendo de España cuando podrían hacerse producciones aquí porque a lo mejor tú no confías en con quien estás trabajando y yo creo que la confianza es la base de todo" (Anunciante 2).

Para Producer Anunciante 2 el problema viene porque "las productoras siempre han tenido que defender cosas que no estaban en la producción". Ese es el motivo por el que aparecen los Cost controller en su opinión.

Lo cierto es que el Cost controller entra en el anunciante cuando existe esa desconfianza. Consultor 4 reconoce que llegan solo para confirmarlo: "Ya tienen indicios antes. Cuando llega nuestro dictamen ya llueve sobre mojado muchas veces".

Consultor 1 afirma que cuando empieza a trabajar "no había Cost controllers todavía. De hecho, ni siquiera se utilizó esa palabra. El cliente me llama porque necesitaba una asesoría para saber cuánto costaban las producciones, porque se habían dado cuenta de que estaban pagando en exceso".

Para el Producer 4 la figura del Cost controller es una forma de "especializar un proceso de compra que a un director de marketing le resulta imposible". Sin embargo, afirma que se supone que ese servicio lo tiene que dar el departamento de producción de la agencia con la que trabaja, y que por tanto todo se reduce "al miedo a que me roben".

Creativo 1 por su parte, entiende los motivos de esa desconfianza:

Yo creo que puede estar legitimada esa falta de confianza. Los clientes pagan cada vez menos, tanto cada vez menos que la situación se hace insostenible, las estructuras se hacen insostenibles y en lugar de poner freno a eso y decir: hasta aquí señores, nosotros no podemos subsistir y renunciar a cuentas (que eso no lo hace nadie), lo que han decidido hacer las agencias, que a mí tampoco es que me parezca bien, es que lo que no les dan, por un lado, lo van a coger por otro. Claro tú ante eso puedes decir: qué sinvergüenzas. Pero alguien ha empezado: un cliente que ha decidido que va a pagar la mitad y que tú no puedes hacer nada.

Para Creativo 3 la situación es la misma que plantea Creativo 1:

Auditar las cuentas está bien siempre y cuando me des ingresos suficientes para que yo pueda mantener mi estructura. Si no me das ingresos suficientes... Entonces empieza el engaño. Empiezan esa serie de mentiras a las que están intentando ponerle control, pero es un control, no están poniendo solución; están poniendo control que no es lo mismo.

Para Productora 4 es un problema de que no se fían, pero también motivado por esa falta de departamentos de producción en las agencias: "Los departamentos de cuentas tampoco saben de producción y mucho menos saben de lo que cuestan las cosas y los Producers que se contratan son gente joven, freelance que tampoco cuentan con el respaldo de la agencia para tomar decisiones". Ninguno de ellos en su opinión puede justificarle a un anunciante muchos de los gastos de las producciones debido a su falta de formación y experiencia. 
Consultor 4 reconoce que sus primeros trabajos se debían sin duda a la inquietud del anunciante. "Tengo la sospecha de que esto no es nada transparente, me gustaría que tú mirases esos números", le decían al contratarle. Y sin duda, la crisis económica propició el auge de este control:

Ya se estaba notando que había un apretón muy fuerte en todo. Y obviamente se encontraban con estos obstáculos, que las agencias no se resignaban a perder cuota de inversión y los anunciantes veían que sus resultados cada vez decrecían más. Empezaban a ver que había allí una relación extraña y unos resultados más bien pobres. Ellos tenían que estar cada vez en más escaparates y no les daba, porque el presupuesto era el mismo (Consultor 4).

Para Consultor 4, la desconfianza del anunciante no siempre se refiere a la agencia:

Otro factor que ha influido mucho en la introducción de un Cost controller es el nivel de corrupción alto que hay en general en toda la sociedad. Muchos de los anunciantes temían a que la adjudicación de ciertos proyectos pudiera tener algún tipo de repercusión o de asignaciones personales, o de cualquier tipo de cuestionamiento que pudiese cuestionar su transparencia.

Con su afirmación se puede entender que también profesionales que trabajan en el ámbito del anunciante, podrían haber salido beneficiados con la adjudicación de sus producciones a determinadas productoras. Consultor 2 incluso afirma que trabajando como Cost controller para un anunciante le llegaron a ofrecer dinero: "Me han ofrecido dinero, pero yo me muero ¿De qué manera luego llegas a un rodaje y exiges o pides? No puedes. La productora te puede decir: lo saco de lo que tú te llevas, tranquilamente". Y Consultor 1 reconoce que también ha pasado por esa situación: "Si me ha pasado que me han dicho: tú ponte 6.000€ para ti y te callas y lo dejas así. Y entonces he dicho: Perdona, estás hablando conmigo, yo soy el anunciante en este momento. Así que cuida mucho lo que dices porque te puedes quedar sin la cuenta".

Asimismo, las productoras entrevistadas han comentado en numerosas ocasiones que hay anunciantes, sobre todo los que llevan años en el sector y han vivido la época de grandes presupuestos de producción, que les exigen cuestiones que no son específicas de la producción. Y aquí surge la duda: ¿La petición de comer en el restaurante más caro se puede considerar labor comercial por parte de la productora, que trata de ganarse la simpatía del que toma las decisiones, o se trata de un abuso por parte del anunciante? Lo cierto es que, en la época actual, con presupuestos cada vez más ajustados, para los Producer entrevistados es una situación que afortunadamente se da cada vez menos. Las productoras asimismo se quejan de que con determinados clientes no te posicionas en buen lugar si no continuas con esas prácticas. Quizás la distinción entre labor comercial y corrupción se pueda establecer en la cantidad del presupuesto que se derive a tales situaciones. Lo que está claro es que no se puede obviar en esta investigación que anunciantes y agencias han pasado por los juzgados imputados por casos de corrupción entre particulares.

Por todos estos motivos, la percepción en el sector está en que son cada vez más los anunciantes que recurren a sus servicios. Para Producer 3 aquellos pocos que 
comenzaron a principios de siglo se han consolidado, y han aparecido algunos más. "Hay más gente que se dedica a esto y más clientes que requieren de ellos", confirma Producer 1. Y lo corrobora Productora 4, afirmando que la figura del Cost controller aparece cada vez más en las producciones que realizan.

\subsection{Labores del Cost controller}

Anunciante 1 reconoce que se cuenta con esta figura solo cuando el volumen de producción les impide asumir la función desde el departamento de publicidad: "Tenemos una carga de trabajo que nos impide llegar a ese nivel, entonces hay una persona especialista en esto, que se dedica a ese trabajo burocrático de análisis de los costes", pero explica que empezaron a contar con estos servicios hace dos años.

El análisis de los presupuestos era la función que ejercía el Cost controller los años que contaron con esta figura en Anunciante 3: "Revisaba todos los presupuestos y sí que nos daba indicaciones cuando veía que algunas cosas no le cuadraban o creía que estaba demasiado altas".

Para Producer Anunciante 1, los años en los que trabajó como Cost controller sus funciones consistían en recibir los presupuestos, revisarlos, y negociarlos con el Producer de la agencia: "Que me bajen esto de aquí, que me justifiquen esto otro. El Producer de la agencia lo hablaba con la productora". Pero todo ello teniendo en cuenta su conocimiento del sector, que saben leer un presupuesto. Y por ello, aclara: "No es un área de compras que te dice que lo bajes un 25\%. De hecho, había veces que si faltaban cosas se les pedía que lo metieran". Su papel no se quedaba en esa revisión del presupuesto y en su caso afirma que acudía a la reunión de preproducción, al rodaje y a la postproducción hasta la entrega de la película terminada.

Al igual que Producer Anunciante 1, Consultor 4 explica que la relación con el Producer de la agencia debe ser constante: "Tienen que estar con una relación muy estrecha. Todo lo que se decida en las otras esferas tiene que ir bien traducido al Producer, pero el Producer es el que tiene que gestionar la producción". Para Consultor 4 el proceso de negociación de un presupuesto es rápido: "Se reduce casi a diez minutos. Porque están hablando entre dos profesionales que saben perfectamente que están ahí para ayudar, para decidir de dónde tienes que quitar y dónde tienes que poner".

Para Consultor 1 esa labor de supervisión del presupuesto tenía una consecuencia clara para su cliente: "Hicimos dos o tres pruebas con dos o tres producciones, y efectivamente se dieron cuenta de que si yo lo revisaba ahorraban mucho dinero". Pero su labor no siempre ha sido bien entendida, y por eso afirma: "Siempre he pretendido que mi labor como Cost controller no sea que nadie me vea como un enemigo sino como un aliado y sobre todo que soy ecuánime con todos. Es una cosa que siempre me ha preocupado mucho y creo que yo lo he conseguido". Aunque también afirma que en alguna ocasión ha tenido que dejar de trabajar para algún anunciante porque no se creía que su agencia le estaba aumentando un porcentaje alto a su producción.

Para las productoras no es fácil razonar con los Cost controller cuando comienzan a cuestionar las distintas partidas de los presupuestos:

Me han discutido partidas de taxis, y he dicho: vamos por administración. Pero eso no les interesa. Porque un presupuesto es un estimado. Pero luego yo juego con un montón de imprevistos: lluvias, mal tiempo, alguien que ha llegado tarde, algo 
que se encalla en el rodaje y, por tanto, tienes que repetir y repetir las tomas. Esas cosas uno las tiene que asumir, medir y calibrar. No es tan sencillo como decir esta partida de taxis está muy alta. (Productora 3)

Para Creativo 2, los Cost controller tienen que demostrar que su trabajo, sus funciones, suponen un ahorro, pero a la vez una mejora de la calidad. "Un Cost controller que pueda avalar con su trabajo que es competitivo y responsable de una bobina. Algo que ayuda en el proceso no solo a ahorrar dinero sino también a mejorar la calidad del resultado final".

Y en esa línea explica Productora 3 que no solo revisan los presupuestos, sino que en ocasiones "ayuda en determinados casos a que los clientes entiendan determinadas cosas".

Para Productora 3 ejerce otro papel: "El anunciante puede seguir siendo el bueno y el Cost controller es el malo". No en vano, el Cost controller no es una figura muy querida en el sector.

Algo inquietante resulta la opinión de Consultor 4:

Si se nos pide opinión nosotros decimos que no nos parecen transparentes algunos procesos, no llegamos a detallar mucho porque tampoco nos interesa destruir todo. El sector tiene que ser saneado, pero no destruido. Es así de claro y es como tiene que funcionar. Solo tenemos que sanear, nada más.

\section{3. ¿En qué momento entra y hasta cuándo está el Cost controller en los procesos de producción?}

Para poder valorar sus funciones es importante aclarar en qué fases consideran los profesionales entrevistados que intervienen los Cost controller.

El Anunciante 2 explica que en su caso empiezan a trabajar cuando la creatividad ya está aprobada y se comienza a buscar productora.

"La fase creativa es todavía una de las pocas partes mágicas que tiene el proceso. Meter una figura que posiblemente la creatividad no es su fuerte donde no va a poder aportar algo que realmente genere esa magia yo creo que no es adecuado. Sobre todo, porque es un momento más íntimo entre la marca y la agencia. Hay que soñar, hay que traer algo grande, si la ambición es grande ya veremos dónde nos quedamos. Pero si tú la ambición ya la pones abajo seguramente el resultado sea todavía más bajo. Entonces vamos a la luna que luego ya veremos si es en un plató, si en vez de la luna es un barrio de aquí que parezca la luna. Pero la idea tiene que surgir y yo en ese proceso creativo no me gusta poner muchas trabas".

Y si en su caso entra cuando se comienza la búsqueda de la productora, también explica que suele permanecer hasta el final de proceso: "Es el único contacto con la productora para ver si realmente lo que tú has pedido, lo que se ha hablado en la PPM está en marcha y va a funcionar".

El resto de los entrevistados coinciden con Anunciante 2 en este momento de comienzo de sus labores, pero no en el que terminan sus funciones. Consultor 1 afirma que de vez en cuando va a los rodajes y que suele estar en la presentación del online. 
Para Creativo 3 desaparecen una vez negociado el presupuesto y no porque el cliente solo pague por esos servicios:

"Lo hace de una forma inteligente. Saben que el dinero que te dan muchas veces no cubre la calidad mínima para un proyecto y lo mejor es desaparecer. De esa cadena de mando desapareces. Si intervienen pueden estar viendo que a veces el presupuesto que hay no da para un determinado nivel de calidad que se está exigiendo. A mí me ha pasado".

Consultor 4 afirma que, en muchos casos, cuando no intervienen en el resto de las fases se debe a que "no quieren porque les falta experiencia".

Lo cierto es que esta afirmación lleva a preguntarse qué tipo de formación deben tener los profesionales que ejercen la labor de Cost controller.

\subsection{Formación del Cost controller}

Para Productora 1 son varios los requisitos que deben cumplir: "No solo tienen que saber de producción, que es obvio, sino también de comunicación y de publicidad. Y tener cierto gusto. Para mí el buen Cost controller es aquel que optimiza costes, pero manteniendo estándares de calidad, y no siempre se da".

También exigente en este aspecto se muestra Producer Anunciante 2:

"Evidentemente es importante tener experiencia integral de todos los procesos. Esto quiere decir no solamente de la pura producción; también tiene que tener una sensibilidad hacia la comunicación, hacia la idea. Tiene que saber interpretar los roles de la agencia y del anunciante. Entender quién es quién y cuál es la responsabilidad de cada uno. Y a mí me parece que es importante que cuelgue su ego, que no se sienta protagonista".

Para Consultor 4 la mayoría de los Cost controller carecen de experiencia en producción o en realización, y en su opinión, es necesario contar con ambas para poder emitir una opinión válida.

De la misma opinión es Producer 4:

"Primero tiene que venderse a su cliente, no como que le va a abaratar, sino como que va a garantizar que los costes son justos. Ser una persona de producción y tener criterio a la hora de ver si los costes son justos. No es cuestión de mirar la cifra al final, sino que hay que mirar el desglose. Ver qué me da cada uno. Entender un tratamiento, ver si es posible. Confirmar que un plan de trabajo es viable. Eso es lo que tiene que hacer un Cost controller".

Producer 2 recoge tres requisitos: "Formación, saber hacer y educación". Y se lamenta de que en España normalmente no es así: "Fuera, el Cost controller es eso, alguien que vela por la calidad y mira costes. Aquí en España es alguien, en su gran mayoría, que solo le preocupa bajar por bajar, muchas veces sin leerse la documentación". 


\subsection{Retribución del trabajo de Cost controller}

El interés por esa reducción de presupuestos es algo muy comentado por todos los entrevistados. Por eso, se ha considerado importante analizar algunas de las explicaciones sobre la forma que tienen las empresas de remunerar el trabajo de los Cost controller.

Anunciante 2 resuelve la incógnita sobre la forma de pago que ellos emplean con su Cost controller. Utilizan dos fórmulas: "O se le da un porcentaje en función de lo que consiga reducir dentro de la producción o se acuerda un fee por anticipado por asegurarnos que va a ser la mejor producción al mejor coste".

Ante la primera situación, el mismo anunciante se plantea los problemas que conlleva esa forma de pago: "No sé si lo que él ha reducido es lo que tenía que reducir, si podría haber ido a más, si podría haber hecho menos, si al reducir me ha cortado calidad". Y continúa: "Hay que fiarse mucho porque al final si tú coges a una persona que su ganancia venga solo de reducir costes obviamente va a tirar más por reducir".

Por tanto, desde hace poco han empezado a darles una cantidad fija independiente del ahorro que consigan. "Así te aseguras que esta persona ya no va a negociar para ganarse su comisión y sí va a negociar en teoría para que sea la mejor producción porque ya tiene su fee", confirma Anunciante 2 .

El problema está en que durante años la primera fue la fórmula habitual. Y eso ha llevado a que en el sector no se considere a estos profesionales como garantes de la mejor producción en ningún caso. De hecho, ante la pregunta de cómo creen que cobran los Cost controller, muchos responden que según la primera fórmula planteada.

Cuentas 1 entiende que "en la mayoría de los casos son personas externas al anunciante que se retribuyen por variables en función de su capacidad de reducir costes y no en función de la buena calidad final de la pieza".

Para Productora 1 es una fórmula sencilla la que puede plantear el Cost controller al anunciante:

Yo he estado en agencia y sé que como mínimo te meten un $15 \%$, de ahí para arriba. Por eso, yo que he sido productor de agencia me voy a revisar los presupuestos y voy a conseguir que por lo menos se te reduzcan en un 10 y hasta en un $15 \%$. De eso yo me llevo una parte, me das un sueldo muy pequeñito y un $5 \%$ de lo que te ahorres, con lo cual, si te ahorro un 15 , te quedas con un $10 \mathrm{y}$ con la tranquilidad de que no te están robando (Productora 1).

En opinión de Creativo 2 esa forma de pago por el ahorro es una fórmula que no debería existir:

Yo creo que eso a lo mejor es una leyenda urbana. En algunos casos puede ser, pero es tan perversa la fórmula que quiero pensar que no, o que va a menos, aunque en algún momento haya podido suceder. También es cierto que hay algunos profesionales que por necesidad de acceder a esa posición han vendido esa fórmula. Una en la que simplemente llevar un porcentaje de lo que ahorren sin ningún compromiso de pago para el que lo contrata ¿no? Pero yo creo que se cae por su peso. Es decir, que no se sostiene un análisis. Entonces quiero pensar que ese modelo tóxico está en desuso. Pero la verdad es que lo desconozco. 
Muchos de ellos afirman que eso era así antes, pero que en la actualidad los anunciantes optan por pagar una cantidad fija independiente del ahorro que se consiga.

Hay un bulo que dice que cobran por lo que ahorran, eso en algunos casos puede ser, pero creo que en general suelen tener un fee por supervisar una producción independientemente de que consigan reducir el presupuesto total. Aunque nunca sabes exactamente cuál es la forma de retribución de su trabajo". (Postproductora 1)

Producer 1 tiene las mismas dudas. Y Productora 3 y 4 aseguran que en la actualidad cobran una tarifa fija por este servicio.

Para Producer 3 el planteamiento no es el adecuado con independencia de la forma de pago: "Iniciaron cobrando lo que descuentan. Ahora hay un fee anual por la supervisión. Pero la base de todo es conseguir un ahorro. La base de todo no es: voy a conseguir la mejor producción al mejor precio. Entonces eso ya empieza mal". Asegura que algunos clientes que no tienen Cost controller le han comentado que esa es la actitud con la que llegan a ofrecer sus servicios. Y ante eso, algunos anunciantes no se quedan con el ahorro que les puede llegar a conseguir, sino que se plantean: “¿Qué resultado voy a tener?”. Y esa actitud, en su opinión, es la que va a acabar con los Cost controller: "El propio fin de su trabajo es el que va a provocar su desaparición. A los Cost controllers les quedan cinco años de vida. Porque va a haber un cambio de modelo y dentro de ese cambio de modelo va a haber un cambio de Cost controller a asesor o Producer".

Quizás por este motivo, y por todos los que se van a ver a continuación, muchos de ellos no quieren ser llamados Cost controller, sino Consultores del anunciante.

Lo que está claro es que los Consultores que trabajan para varios anunciantes y los Cost controller entrevistados aseguran que en ningún caso han acordado el modelo de retribución de acuerdo a los descuentos obtenidos. Consultor 1 afirma que, aunque le consta que muchos de los Cost controller cobran por lo que ahorran, en su caso no es así:

Lo dije muy claro con todos mis anunciantes, yo no cobro por comisión. Me niego. Jamás he querido cobrar una comisión porque eso, quieras que no, da lugar a que piensen, aunque sea mentira, aunque en ocasiones es verdad. Yo tengo una tarifa fija y si ahorro $100.000 €$ o $15.000 €$ yo voy a cobrar lo mismo. Porque no quiero que nadie piense que yo me llevo una comisión de nadie, ni que nadie pueda imputarme ningún tipo de corrupción por mínima que sea. (...) Hay Cost controllers que le exigen un porcentaje a la productora. Es que lo sé. Me consta. (Consultor 1)

Consultor 4, que como ya se ha comentado trabaja para varios anunciantes, afirma que es una fórmula que no debe darse:

Eso es nefasto, eso es poco honesto. Nuestra política es que no haya ninguna vinculación de lo que puede ser el logro del análisis que se haya hecho, a lo que es el resultado económico del asunto. Nosotros aplicamos una tarifa fija, independientemente de que ahorremos seis millones o que ahorremos seis euros. Es así de claro. Eso es lo más honesto y lo más transparente. 


\section{Conclusiones}

Como resultado de la presente investigación, se puede afirmar que los anunciantes se habrían planteado recurrir cada vez con mayor asiduidad a Cost controllers y Consultores para ajustar los presupuestos de producción audiovisual.

Cada vez son más las empresas que recurren a los servicios de Consultoría y son distintos los perfiles de los profesionales que realizan esta labor. Analizadas las funciones del Cost controller, el Consultor y el Producer del anunciante, se considera que contar con un profesional de la producción en la propia estructura del anunciante que vele por la mejor calidad al mejor precio, es beneficioso para la producción.

Asimismo, la figura del Producer del anunciante no debe estar reñida con la del Producer de agencia, sino todo lo contrario; teniendo en cuenta la enorme inversión en medios que realiza un anunciante, resulta conveniente contar con las dos figuras durante el proceso: un Producer de anunciante facilitaría la producción al contar con un interlocutor por parte del cliente que entendiera todo aquello que le plantee de forma transparente un Producer de agencia. Y este, al mismo tiempo, podría trabajar de la mano del creativo aportando todos sus conocimientos para conseguir una mayor calidad con el presupuesto adjudicado a cada producción. Entre todos, se podría conseguir así un resultado final mucho mejor que el obtenido en las producciones actuales en las que todos desconfían de los motivos de los demás.

Otra cuestión es procurar la correcta formación de estos profesionales, considerando que en muchos casos han sido relegados de sus funciones y ya no pueden enseñar a los jóvenes la realidad de una profesión que, por unos motivos u otros, en los últimos años ha sido vapuleada y menospreciada.

\section{Bibliografía}

Alameda, D.; Benavides, J.; Fernández Blanco, E.; Villagra, N. (2010). Los anunciantes españoles y el nuevo contexto de comunicación: una aproximación cualitativa. Revista Latina de Comunicación Social, 65. Universidad de La Laguna, 159-175. DOI: 10.4185/ RLCS-65-2010-890-159-175. Disponible en: https://goo.gl/p3bvpp [Consulta junio 2017]

Brierley, S. (2005). The advertising handbook. London: Routledge.

Carvajal, A. (2009). Evolución de los elementos formales de la composición y la estética filmica publicitaria a finales del siglo XX en España (1986-2003). Tesis doctoral. Universidad Complutense de Madrid.

(2016). El proceso de producción audiovisual. Sevilla: Punto Rojo Libros.

Cury, I. (2013). TV commercials: How to make them ( $1^{\mathrm{a}}$ ed.). Burlington: Focal Press.

García-Clairac, S. (2005). Realización de spots publicitarios. Córdoba: Almuzara.

InfoAdex. (2009). Resumen. Estudio de la inversión publicitaria en España.

Ruiz Olabuénaga, J.I. (2012). Metodología de la investigación cualitativa (5ª ed.). Bilbao: Universidad de Deusto.

Solanas, I.; Sabaté, J. (2011). Dirección de cuentas: Gestión y planificación de cuentas en publicidad. Barcelona: Editorial UOC. 
Under Control Producers, el Producer del anunciante. (2015). IPMARK. Disponible en: https://goo.gl/jWSB4a [Consulta junio 2017].

Valles, Miguel S. (2002). Entrevistas cualitativas. Madrid: Centro de Investigaciones Sociológicas.

(2009). Técnicas cualitativas de investigación social: Reflexión metodológica y práctica profesional ( $4^{\mathrm{a}}$ reimp. ed.). Madrid: Síntesis. 